\title{
A Novel Reduced Graphene Oxide Modified Carbon Paste Electrode for Potentiometric Determination of Trihexyphenidyl Hydrochloride in Pharmaceutical and Biological Matrices
}

\author{
Josip Radić $^{1}\left(\mathbb{D}\right.$, Maša Buljac $^{1}\left(\mathbb{D}\right.$, Boštjan Genorio $^{2}$,, Ema Gričar ${ }^{3}$ and Mitja Kolar ${ }^{3, *(\mathbb{C}}$ \\ 1 Department of Environmental Chemistry, Faculty of Chemistry and Technology, R. Boškovića 35, \\ 21000 Split, Croatia; jradic@ktf-split.hr (J.R.); masa@ktf-split.hr (M.B.) \\ 2 Department of Chemical Engineering and Technical Safety, Faculty of Chemistry and Chemical Technology, \\ University of Ljubljana, Večna pot 113, 1000 Ljubljana, Slovenia; bostjan.genorio@fkkt.uni-lj.si \\ 3 Department of Chemistry and Biochemistry, Faculty of Chemistry and Chemical Technology, \\ University of Ljubljana, Večna pot 113, 1000 Ljubljana, Slovenia; ema.gricar@fkkt.uni-lj.si \\ * Correspondence: mitja.kolar@fkkt.uni-lj.si
}

\section{check for}

updates

Citation: Radić, J.; Buljac, M.; Genorio, B.; Gričar, E.; Kolar, M. A Novel Reduced Graphene Oxide Modified Carbon Paste Electrode for Potentiometric Determination of Trihexyphenidyl Hydrochloride in Pharmaceutical and Biological Matrices. Sensors 2021, 21, 2955. https://doi.org/10.3390/s21092955

Academic Editors: Isabel Sayago, José Pedro Santos and Tiziana Polichetti

Received: 19 March 2021

Accepted: 19 April 2021

Published: 23 April 2021

Publisher's Note: MDPI stays neutral with regard to jurisdictional claims in published maps and institutional affiliations.

Copyright: (c) 2021 by the authors. Licensee MDPI, Basel, Switzerland. This article is an open access article distributed under the terms and conditions of the Creative Commons Attribution (CC BY) license (https:// creativecommons.org/licenses/by/ $4.0 /)$.

\begin{abstract}
A novel promising carbon paste electrode with excellent potentiometric properties was prepared for the analysis of trihexyphenidyl hydrochloride (THP), the acetylcholine receptor and an anticholinergic drug in real samples. It contains $10.2 \%$ trihexyphenidy-tetraphenylborate ionic pair as the electroactive material, with the addition of $3.9 \%$ reduced graphene oxide and $0.3 \%$ of anionic additive into the paste, which consists of $45.0 \%$ dibutylphthalate as the solvent mediator and $40.6 \%$ graphite. Under the optimized experimental conditions, the electrode showed a Nernstian slope of $58.9 \pm 0.2 \mathrm{mV} /$ decade with a regression coefficient of 0.9992 . It exhibited high selectivity and reproducibility as well as a fast and linear dynamic response range from $4.0 \times 10^{-7}$ to $1.0 \times 10^{-2} \mathrm{M}$. The electrode remained usable for up to 19 days. Analytical applications showed excellent recoveries ranging from 96.8 to $101.7 \%$, LOD was $2.5 \times 10^{-7} \mathrm{M}$. The electrode was successfully used for THP analysis of pharmaceutical and biological samples.
\end{abstract}

Keywords: potentiometry; carbon paste electrode; reduced graphene oxide; trihexyphenidyl hydrochloride; pharmaceuticals; urine samples

\section{Introduction}

Trihexyphenidyl hydrochloride (THP), the muscarinic acetylcholine receptor antagonist [1], is a synthetic anticholinergic drug that selectively blocks the cholinergic nerve pathway of the striatum [2]. It was approved by the Food and Drug Administration in 2003 for the symptomatic treatment of Parkinson's disease [3]. It is also commonly used to reduce extrapyramidal side effects occurring during antipsychotic treatment. Typically, patients receive $2-15 \mathrm{mg}$ of the drug daily. It is reported that the drug does not accumulate in tissues [4], as $60 \%$ of the dose is rapidly excreted in the urine [5]. Therefore, the expected drug concentration in urine is $2.4 \times 10^{-6}$ to $1.8 \times 10^{-5} \mathrm{~mol} \mathrm{~L}^{-1}$.THP is a white powder, soluble in chloroform and methanol, sparingly soluble in methylene chloride and slightly soluble in water [6]. THP is chemically described as 1-cyclohexyl-1-phenyl-3-(1-piperidyl)1-propanol hydrochloride with molecular formula $\mathrm{C}_{20} \mathrm{H}_{31} \mathrm{NOxHCl}$ and molar mass of $337.9 \mathrm{~g} \mathrm{~mol}^{-1}$.

The therapeutic importance of THP has led to the development of several analytical methods for its determination and quantification, both in pharmaceutical formulations and biological fluids, including gas chromatography [7-10], either reversed-phase high performance liquid chromatography [11,12] or high-performance liquid chromatography $[13,14]$, liquid chromatography coupled with mass spectrometry [15-17], spectrophotometry [6,18], radioimmunoassay [4], capillary electrophoresis [19-21], gravimetry [22], and polarograpy [23]. The use of most of the above techniques usually requires several 
time-consuming manipulation steps, trained personnel to work on the instruments, and expensive equipment. On the other hand, potentiometric sensors have been widely used for the determination of various species due to their relatively high sensitivity, selectivity, rapid response, applicability to turbid and colored solutions, adaptability to on-line analytical systems, and small sample volume [24-30]. Therefore, ion-selective electrodes have found applications in clinical, industrial, and environmental analysis [31]. One of the most common procedures for the development of ISE (for the determination of drugs, whether the active ingredient is a component of pharmaceutical preparations or biological fluids) is the incorporation of a lipophilic ion-pair-associated complex into a polyvinyl chloride (PVC) based membrane [31-35] or the preparation of carbon paste electrodes (CPE) $[5,24,30,31,36-44]$.

However, PVC based membranes exhibit several disadvantages, such as leaching of plasticizers and membrane ionophores, limited adhesion of supporting materials in addition to high water uptake $[45,46]$. On the other hand, CPE are easier to fabricate. They show faster responses with simple surface renewability and also have lower ohmic resistance [41].

In the literature, there is only one work on the determination of THP using a carbon paste electrode [5]. Since nanomaterials are playing an increasingly important role in the fabrication of chemo- and bio-sensors $[24,31,47-50]$ due to the possibility of their direct and easy incorporation into ion-selective membranes, synthesized reduced graphene oxide $(\mathrm{rGO})$ was used in this work. A sensor for the determination of THP containing any type of nanomaterials has not yet been developed according to the available literature. rGO is a widely used component in electrochemical measurements due to its uncomplicated synthesis, high electrical conductivity, light weight, high specific surface area, strong mechanical strength, and chemical stability [24,28,51-53]. Additionally, when compared to graphene it is significantly cheaper, while it exhibits similar properties, and it is unquestionably more conductive than graphene oxide and as such the most appropriate choice to use in electrochemical sensing applications.

The present study describes the development and application of a carbon paste electrode chemically modified with trihexyphenidyl for the selective and sensitive determination of THP in pure solutions, pharmaceutical (Parkopan tablets) and biological (urine) samples. The results confirm that the prepared electrode exhibits excellent selectivity for THP, wide concentration range, low detection limit, fast response time and reproducibility, which are the most important performance factors of the electrode besides the absence of special pretreatment steps.

\section{Materials and Methods}

\subsection{Equipment}

Morphology characterization of graphite oxide (GO) and rGO was performed using a scanning field emission electron microscope Zeiss ULTRA plus FE-SEM (Jena, Germany). SEM images were acquired at $2 \mathrm{kV}$ using InLens or SE2 detector at WD $5.5 \mathrm{~mm}$. Elemental analysis of the samples was done inside SEM using EDS analysis with an Oxford X-Max SDD detector (Wycombe, UK), processed with INCA software (Wycombe, UK). EDS analysis was carried out at $20 \mathrm{kV}$.

Specific surface area $\left(\mathrm{m}^{2} / \mathrm{g}\right)$ was measured by $\mathrm{N}_{2}$ adsorption at $77 \mathrm{~K}$ on an ASAP 2020 Micromeritics (Norcross, GA, USA) instrument using the BET analysis method. Samples were degassed under vacuum (5 millitorr) at $120^{\circ} \mathrm{C}$ for $2 \mathrm{~h}$.

Microanalyses were performed by combustion analysis on a Perkin-Elmer CHN Analyzer 2400 II.

Potentiometric measurements were performed using the digital $\mathrm{pH} / \mathrm{mV}$ meter model Seven Easy (Mettler-Toledo, GmbH, Schwerzenbach, Switzerland). The electrochemical cell was completed with an external Ag/ AgCl reference electrode, model InLab ${ }^{\circledR}$ Reference51343190 (Mettler-Toledo GmbH, Schwerzenbach, Switzerland). A Premium hotplate 
stirrer model MSH-20A (Witeg Labortechnik, GmbH, Wertheim, Germany) was used for stirring the solutions.

Measurements of the $\mathrm{pH}$ values of the solutions were performed using a $\mathrm{pH}$ electrode InLab Expert Pro (Mettler Toledo GmbH, Greifensee, Switzerland).

\subsection{Chemicals and Materials}

All chemicals and reagents were of the analytical grade and double distilled deionized water was used throughout experiments.

Graphite flakes (Timrex KS 44) were purchased from Imerys Graphite \& Carbon (Bodio, Switzerland). Dibutylphthalate (DBP), phosphotungstic acid hydrate (PTA), maprotiline hydrochloride, and THP were purchased from Sigma (USA). Sodium tetraphenylborate (NaTPB), zinc nitrate hexahydrate, magnesium nitrate hexahydrate, acetylsalicylic acid, glucose, galactose, and fructose were purchased from Merck (Germany). Paracetamol was kindly provided by Galenic laboratory Split-Dalmatia County Pharmcy (Croatia). Sodium acetate anhydrous was purchased from Gram-mol (Croatia); glacial acetic acid, potassium nitrate, calcium nitrate tetrahydrate, iron (III) nitrate nonahydrate, and lead(II) nitrate from Kemika (Croatia); silver nitrate and ammonium chloride from Sigma-Aldrich (Germany). Parkopan ( $2 \mathrm{mg} /$ tablet) used in the application of the prepared electrode was obtained from the local drugstore.

\subsection{Procedures}

Stock solutions of $1.0 \times 10^{-2} \mathrm{M}$ THP were prepared in a $50 \mathrm{~mL}$ volumetric flask by dissolving $168.9 \mathrm{mg}$ of THP a small volume of acetate buffer heated to $30^{\circ} \mathrm{C}$ and making up the volume with acetate buffer at room temperature. Working solutions were prepared by serial dilution. Interfering stock solutions of $1.0 \times 10^{-2} \mathrm{M}$ for each of $\mathrm{K}^{+}, \mathrm{NH}_{4}{ }^{+}, \mathrm{Ca}^{2+}$, $\mathrm{Mg}^{2+}, \mathrm{Zn}^{2+}, \mathrm{Pb}^{2+}, \mathrm{Fe}^{3+}$, glucose, galactose, fructose, acetylsalicylic acid, paracetamol, and maprotiline hydrochloride were prepared by dissolving the appropriate amount of the compounds and subsequent dilutions, where necessary. All solutions and dilutions were prepared in a $1.5 \times 10^{-2} \mathrm{M}$ solution of acetate buffer $\mathrm{pH} 4$ by diluting glacial acetic acid $(0.570 \mathrm{~mL})$ and sodium acetate $(452 \mathrm{mg})$ in distilled water using a $1000 \mathrm{~mL}$ volumetric flask.

THP has a high affinity for forming IAC with the oppositely charged ion pairing agent NaTPB (Figure 1). The precipitated ion pair associated complex (IAC) was used as the sensing material of the electrode.

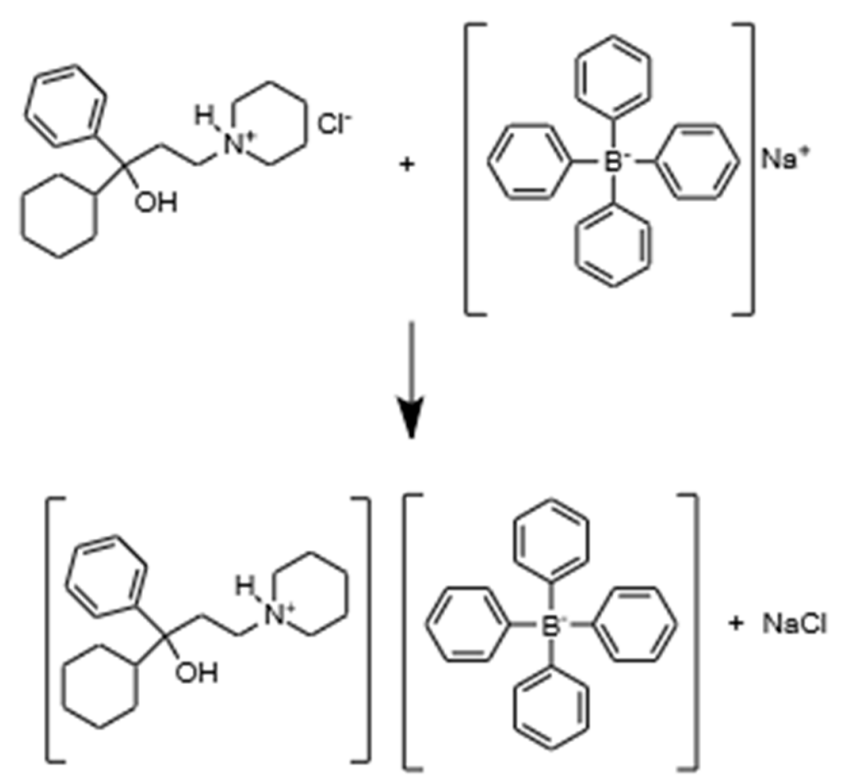

Figure 1. Proposed schematic diagram of reaction between $\mathrm{THP} \times \mathrm{HCl}$ and $\mathrm{NaTPB}$ ion pair associated complex as sensing element. 
It was prepared by dissolving $67.6 \mathrm{mg}$ of THP in $20 \mathrm{~mL}$ of distilled water heated to $30{ }^{\circ} \mathrm{C}$. A solution of NaTPB was prepared by dissolving $68.5 \mathrm{mg}$ of NaTPB in $20 \mathrm{~mL}$ of distilled water. Twenty $\mathrm{mL}$ of the THP solution was slowly added to $20 \mathrm{~mL}$ of the NaTPB solution. The resulting white precipitate was filtered, washed thoroughly with distilled water (until negative reaction to chloride ions), covered, and dried at room temperature for at least $72 \mathrm{~h}$. The dried precipitate was then ground to obtain a fine powder which was used as a sensing element in the electrode.

The chemical compositions of the precipitate were confirmed by elemental CHN analysis. The $\mathrm{C}, \mathrm{H}$, and $\mathrm{N}$ contents of the trihexaphenidyl-tetraphenylborate ion associated complex (THP-TPB) were $85.14 \%, 7.85 \%$, and $2.20 \%$, respectively. Compared to the corresponding calculated values of $84.99 \%, 8.45 \%$, and $2.25 \%$, this confirms that the combination rate of the prepared THP-TPB ion pair was 1:1.

GO was synthesized by the improved Hummer's method [54]. $\mathrm{KMnO}_{4}(10 \mathrm{~g})$ was slowly added to a mixture of $\mathrm{H}_{2} \mathrm{SO}_{4}(357 \mathrm{~mL})$ and $\mathrm{H}_{3} \mathrm{PO}_{4}(40.2 \mathrm{~mL})$. Upon cooling to room temperature, $10 \mathrm{~g}$ of graphite flakes was added to the reaction mixture. Over the next five days, $\mathrm{KMnO}_{4}$ was added in 6 aliquots. The reaction was then quenched by addition of $500 \mathrm{~mL}$ of crushed ice and $\mathrm{H}_{2} \mathrm{O}_{2}(30 \mathrm{~mL})$. The mixture was transferred to plastic centrifuge bottles, diluted with $\mathrm{H}_{2} \mathrm{O}$, and centrifuged (4100 rpm for $30 \mathrm{~min}$ ). The supernatant was decanted and the remaining solid washed with $\mathrm{H}_{2} \mathrm{O}$ and centrifuged (4100 rpm for $30 \mathrm{~min}$ ). This washing-centrifuging cycle was performed until the supernatant reached the $\mathrm{pH}$ value of 5.0 or more. The remaining material then was freeze-dried and stored at room temperature.

Dried GO was dissolved in purified water using an ultrasonic bath and placed under a water-cooled reflux system with continuous stirring. Twenty $\mathrm{mL}$ of hydrazine hydrate was slowly added to carry out the reduction of GO. The mixture was heated in an oil bath at $100{ }^{\circ} \mathrm{C}$ for $24 \mathrm{~h}$. rGO, a black solid, was then filtered hot and washed with $500 \mathrm{~mL}$ boiling water. The synthesized reduced graphene oxide (rGO) was further used for the fabrication of electrodes.

The electrodes were investigated by varying the ratios $(w / w)$ of graphite, IAC, $\mathrm{rGO}$, solvent mediator, and anionic additive, until the optimum composition that exhibits the best response characteristics was achieved. According to the literature, all the components were made homogenous in an agate mortar $[36,45]$. The obtained smooth paste was carefully packed into a laboratory made polytetrafluoroethylene electrode body (Teflon holder) (Figure S1, Supplementary Materials). Before use, the external surface of the carbon paste was polished with circular motions on parafilm until the surface had a shiny appearance. Finally, the electrodes were conditioned by soaking in an acetate buffer solution for $1 \mathrm{~h}$ before potentiometric measurements.

All potentiometric measurements by the MCPE were performed with the following cell configuration at room temperature:

$\mathrm{Ag} / \mathrm{AgCl}$ (saturated)/ / sample solution/carbon paste/stainless-steel rod.

For calibration, the conditioned electrodes were separately immersed in $20 \mathrm{~mL}$ of each of the working standard solutions. The properties of the electrodes were investigated by measuring the change in the potential value of the THP solutions whose concentrations were changed in an ascending manner from the lowest of $6.3 \times 10^{-8}$ to the highest one of $1.0 \times 10^{-2} \mathrm{M}$. Potential readings were plotted as a function of the negative logarithm of the THP concentration. An electrode that showed the Nernstian slope and the widest linear range was used for further examination of the electrode properties.

THP was determined in $50 \mathrm{~mL}$ of the prepared aliquot by the standard addition method. Data were plotted as the numerical expression $10^{\frac{E}{S}} \times\left(V_{A}+V_{S}\right)$ versus $\frac{c_{S} \times V_{S}}{V_{A}}$, where $V_{A}$ was the concentration of the tested aliquot, and $V_{S}$ was the sum of increments of the standard THP solution added in the aliquot for each recorded potential change. The concentration of the standard THP solution added in the aliquot, the slope of the calibration curve, and the recorded potential were labeled as $c_{S}, S$, and $E$, respectively. 
The intersection of the extrapolated segment of the obtained graph and $\frac{\mathcal{c}_{S} \times V_{S}}{V_{A}}$-axis represented the negative value of the concentration of the THP in the aliquot.

The fabricated electrode was immersed in a $50 \mathrm{~mL}$ aliquot and the potential was recorded. A volume of $50 \mathrm{~mL}$ aliquot with concentration of $1.0 \times 10^{-4} \mathrm{M}$ and $1.0 \times 10^{-5} \mathrm{M}$ was titrated against $3.3 \times 10^{-5} \mathrm{M}$ solution of PTA and $1.0 \times 10^{-3} \mathrm{M}$ solution of NaTPB, respectively, with small increments from $25 \mu \mathrm{L}$ to $250 \mu \mathrm{L}$ of titrant. The potentials were monitored after each addition and used to plot the titration curve and consequently calculate the THP concentration.

Twenty-five weighed Parkopan tablets (50.0 mg of THP) were pulverized in a mortar and thoroughly transferred to $500 \mathrm{~mL}$ of acetate buffer solution previously heated to $30^{\circ} \mathrm{C}$. The mixture was shaken for about $60 \mathrm{~min}$ and filtered. The resulting filtrate $\left(3.3 \times 10^{-4} \mathrm{M}\right.$ of THP) was diluted to obtain $1.0 \times 10^{-4}, 1.0 \times 10^{-5}$ and $1.0 \times 10^{-6} \mathrm{M}$ of THP, respectively.

Twenty-five $\mathrm{mL}$ urine samples were spiked with $50 \mu \mathrm{L}, 500 \mu \mathrm{L}$, and $5 \mathrm{~mL}$ of $1.0 \times 10^{-3} \mathrm{M}$ $\mathrm{THP}$, respectively, and transferred to $50 \mathrm{~mL}$ volumetric flasks. The volumes were made up to the marks with acetate buffer to obtain $1.0 \times 10^{-4}, 1.0 \times 10^{-5}$ and $1.0 \times 10^{-6} \mathrm{M}$ of THP, respectively.

\section{Results and Discussion}

\subsection{Characterization of $G O$ and $r G O$}

$\mathrm{GO}$ and rGO were morphologically characterized by SEM. Figure $2 \mathrm{a}, \mathrm{b}$ clearly shows the layered structure of the GO and rGO with high specific surface area. The flakes have a diameter of several $\mu \mathrm{m}$ and are highly wrinkled, especially rGO. Moreover, the rGO flakes have porosity inside the worm-shaped particles, which is advantageous for sensing applications. The existence of worm-shaped particles was confirmed with XRD analysis (Figure S2). The high specific surface area of rGO was confirmed by BET analysis and was $369 \mathrm{~m}^{2} / \mathrm{g}$. However, the specific surface area of GO was 10 times smaller $\left(37 \mathrm{~m}^{2} / \mathrm{g}\right)$ than that of rGO, indicating that chemical reduction of GO provides additional exfoliation of rGO. EDS analysis of rGO revealed the chemical composition of the material (Figure 2c), quantification (in Figure 2d), and that the majority of oxygen functionalities were reduced during the reduction of GO. The latter indirectly suggests that the graphene structure was partially restored. Thorough elemental analysis was performed using ICP-MS (Table S1). Interestingly, we identified residual nitrogen $(8 \mathrm{wt} \%)$ that could be incorporated during the reduction with hydrazine and residual $\mathrm{Mn}$ impurities $(<1 \mathrm{wt} \%)$ introduced during the oxidation step with $\mathrm{KMnO}_{4}$. Both elements were reported to be beneficial for enhanced sensing applications as discussed in previous reports [55-57]. Additionally, Raman (Figure S3), TGA (Figure S4), FTIR (Figure S5), and XPS (Figure S6 and Table S2) experiments were performed to further characterize the prepared materials. 


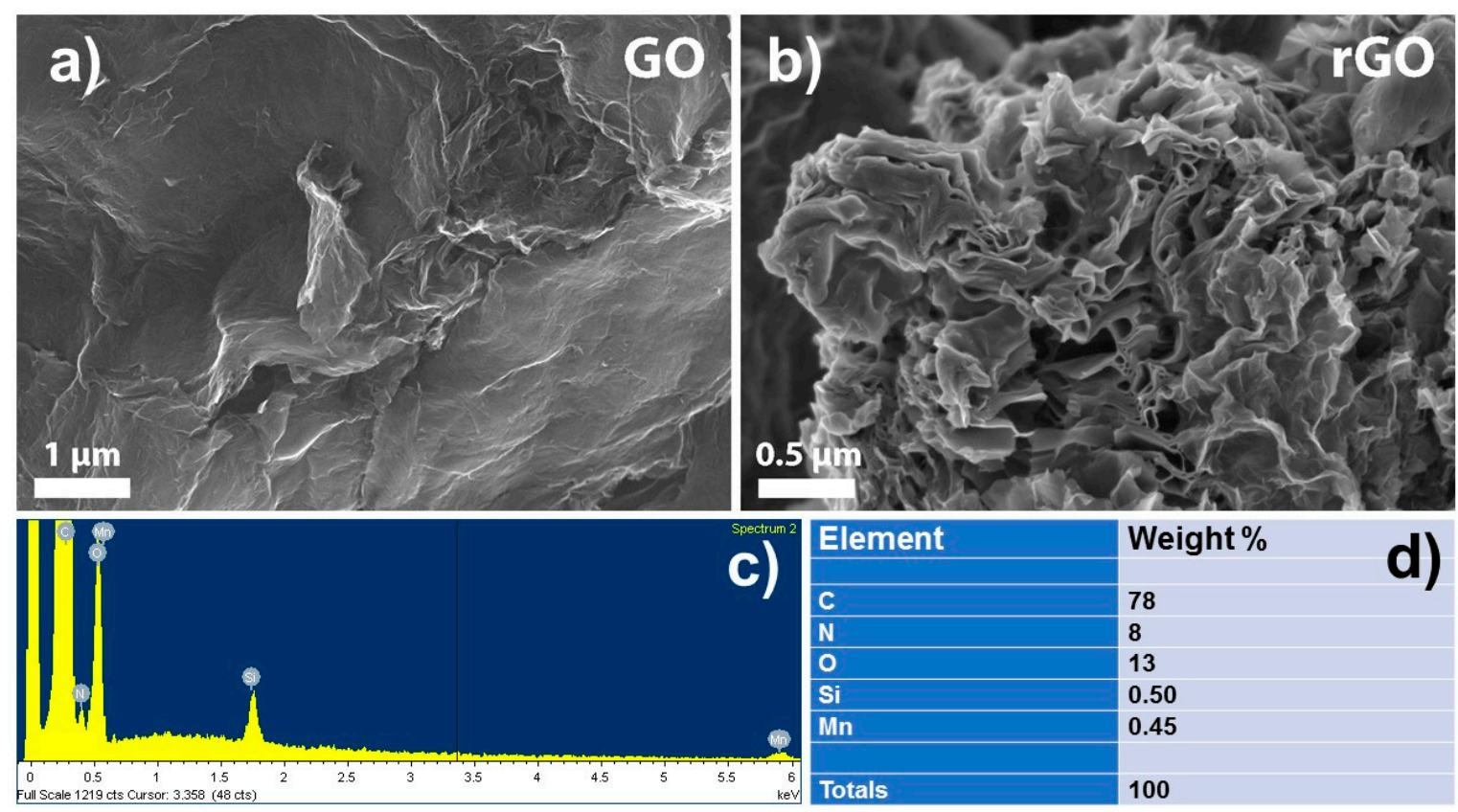

Figure 2. SEM images of: (a) graphite oxide (GO) and (b) reduced graphene oxide (rGO). EDS analysis of reduced graphene oxide (rGO): (c) EDS spectra and (d) quantification.

\subsection{Potentiometric Measurements}

\subsubsection{Optimization of Carbon Paste Electrode Composition}

In general, and from reported articles, it is evident that both the selected organic compound $[38,39,58,59]$, usually used as a precipitating agent for IAC, and binder $[30,37,39,40]$ strongly influence the response of CPE and its characteristics. Various studies and citations can be found in the literature with binder proportions, but all of them in a range between 15 and $55 \mathrm{wt} \%[27,30,36,58,60]$. In this work, NaTPB was used as the anionic precipitating agent, since it was reported that the most suitable CPE electrodes for the determination of THP are those that contain the THP-TPB as IAC [5] in their composition. Therefore, DBP was chosen as the solvent mediator. However, according to the available literature, reduced graphene oxide has not yet been used in CPEs for the determination of THP.

The electrode characteristics were measured using different ratios of carbon paste components. The response characteristics of different CPEs to obtain the lowest possible limit of detection (LOD), wider linear range, and higher regression coefficient are illustrated in Table 1. The unmodified CPE displayed no measurable response to THP (no. 1-4). Electrodes no. 6-13 were prepared using THP-TPB as the recognition ion-pair. Variable amounts of IAC were tested to find the best composition. The results clearly showed that there are no significant changes in the response characteristics of the electrodes containing between 1 and $14.5 \mathrm{wt} \%$ of IAC. However, electrodes with 8.1 and $10.2 \mathrm{wt} \%$ of IAC showed a slightly higher slope.

Based on the published results [5,30,39,40,61], a sufficient amount of lipophilic additive was added in this study to further improve the CPE characteristics (no. 14-20.) The presence of 0.1 or $0.3 \mathrm{wt} \%$ of $\mathrm{NaTPB}$, increased the sensitivity and linear range of the electrode. A change in the slope value from -50.2 to -54.3 or $-54.6 \mathrm{mV} /$ decade and from -50.0 to -55.1 or $-55.7 \mathrm{mV}$ /decade was observed, respectively. CPE saturated with NaTPB as a lipophilic additive (no. 16, 17 and 20) showed a lower slope. Finally, the addition of synthesized rGO significantly improved the electrode characteristics and increased the sensitivity to a Nernstian slope of $-58.9 \mathrm{mV} /$ decade (no. 24, Figure 3). As a result, $40.6 \%$ graphite, $45.0 \%$ DBP, $10.2 \%$ IAC, $0.3 \%$ NaTPB, and 3.9\% rGO were used as the best composition to prepare CPE for further measurements. 
Table 1. Carbon paste composition optimization for direct potentiometric determination of THP.

\begin{tabular}{|c|c|c|c|c|c|c|c|c|c|}
\hline \multirow{2}{*}{$\begin{array}{l}\text { CPE } \\
\text { (no.) }\end{array}$} & \multicolumn{5}{|c|}{ Ingredient (\%) } & \multirow{2}{*}{$\begin{array}{l}\text { Linear Range } \\
\left(\mathrm{mol} \mathrm{L}^{-1}\right)\end{array}$} & \multirow{2}{*}{$\begin{array}{l}\text { Detection Limit } \\
\quad\left(\mathrm{mol} \mathrm{L}^{-1}\right)\end{array}$} & \multirow{2}{*}{$\begin{array}{c}\text { Slope (mV/dec) } \\
\pm \mathrm{SD}^{*}\end{array}$} & \multirow{2}{*}{$R^{2}$} \\
\hline & G & DBP & IAC & NaTPB & rGO & & & & \\
\hline 1 & 59.8 & 40.2 & - & - & - & - & - & $-12.4 \pm 0.7$ & 0.8849 \\
\hline 2 & 55.3 & 44.7 & - & - & - & - & - & $-17.0 \pm 0.9$ & 0.9046 \\
\hline 3 & 51.8 & 48.2 & - & - & - & - & - & $-14.6 \pm 0.8$ & 0.8963 \\
\hline 4 & 45.2 & 54.8 & - & - & - & - & - & $-9.7 \pm 0.7$ & 0.8395 \\
\hline 5 & 54.1 & 45.6 & 0.3 & - & - & $6.3 \times 10^{-6}-1.0 \times 10^{-2}$ & $4.7 \times 10^{-6}$ & $-38.1 \pm 0.6$ & 0.9892 \\
\hline 6 & 53.5 & 45.1 & 1.0 & - & - & $2.5 \times 10^{-6}-1.0 \times 10^{-2}$ & $2.4 \times 10^{-6}$ & $-45.5 \pm 0.3$ & 0.9972 \\
\hline 7 & 52.0 & 46.5 & 1.5 & - & - & $2.5 \times 10^{-6}-1.0 \times 10^{-2}$ & $2.0 \times 10^{-6}$ & $-46.5 \pm 0.5$ & 0.9935 \\
\hline 8 & 50.6 & 46.5 & 2.9 & - & - & $2.5 \times 10^{-6}-1.0 \times 10^{-2}$ & $2.0 \times 10^{-6}$ & $-47.8 \pm 0.3$ & 0.9976 \\
\hline 9 & 49.8 & 44.5 & 5.7 & - & - & $2.5 \times 10^{-6}-1.0 \times 10^{-2}$ & $2.2 \times 10^{-6}$ & $-48.3 \pm 0.6$ & 0.9921 \\
\hline 10 & 47.6 & 44.3 & 8.1 & - & - & $2.5 \times 10^{-6}-1.0 \times 10^{-2}$ & $2.2 \times 10^{-6}$ & $-50.2 \pm 0.3$ & 0.9977 \\
\hline 11 & 44.9 & 44.9 & 10.2 & - & - & $2.5 \times 10^{-6}-1.0 \times 10^{-2}$ & $2.1 \times 10^{-6}$ & $-50.0 \pm 0.3$ & 0.9980 \\
\hline 12 & 43.3 & 44.7 & 12.0 & - & - & $2.5 \times 10^{-6}-1.0 \times 10^{-2}$ & $2.0 \times 10^{-6}$ & $-49.4 \pm 0.3$ & 0.9981 \\
\hline 13 & 40.5 & 45.0 & 14.5 & - & - & $2.5 \times 10^{-6}-1.0 \times 10^{-2}$ & $2.4 \times 10^{-6}$ & $-48.1 \pm 0.3$ & 0.9982 \\
\hline 14 & 46.8 & 45.0 & 8.1 & 0.1 & - & $1.0 \times 10^{-6}-1.0 \times 10^{-2}$ & $9.3 \times 10^{-7}$ & $-53.9 \pm 0.2$ & 0.9990 \\
\hline 15 & 46.3 & 45.4 & 8.0 & 0.3 & - & $1.0 \times 10^{-6}-1.0 \times 10^{-2}$ & $7.9 \times 10^{-7}$ & $-54.5 \pm 0.2$ & 0.9993 \\
\hline 16 & 45.4 & 45.5 & 8.2 & 0.9 & - & $2.5 \times 10^{-6}-1.0 \times 10^{-2}$ & $2.3 \times 10^{-6}$ & $-50.2 \pm 0.4$ & 0.9964 \\
\hline 17 & 44.6 & 44.9 & 8.3 & 2.2 & - & $6.3 \times 10^{-6}-1.0 \times 10^{-2}$ & $4.5 \times 10^{-6}$ & $-46.8 \pm 0.5$ & 0.9957 \\
\hline 18 & 44.8 & 45.0 & 10.1 & 0.1 & - & $1.0 \times 10^{-6}-1.0 \times 10^{-2}$ & $6.6 \times 10^{-7}$ & $-54.6 \pm 0.4$ & 0.9970 \\
\hline 19 & 44.1 & 45.4 & 10.2 & 0.3 & - & $1.0 \times 10^{-6}-1.0 \times 10^{-2}$ & $7.1 \times 10^{-7}$ & $-55.6 \pm 0.3$ & 0.9983 \\
\hline 20 & 43.5 & 45.4 & 10.1 & 1.0 & - & $2.5 \times 10^{-6}-1.0 \times 10^{-2}$ & $1.7 \times 10^{-6}$ & $-51.2 \pm 0.4$ & 0.9976 \\
\hline 21 & 44.3 & 45.3 & 10.0 & 0.3 & 0.1 & $1.0 \times 10^{-6}-1.0 \times 10^{-2}$ & $7.6 \times 10^{-7}$ & $-55.8 \pm 0.4$ & 0.9968 \\
\hline 22 & 43.8 & 45.4 & 10.1 & 0.2 & 0.5 & $1.0 \times 10^{-6}-1.0 \times 10^{-2}$ & $7.5 \times 10^{-7}$ & $-56.8 \pm 0.2$ & 0.9992 \\
\hline 23 & 42.3 & 45.2 & 10.2 & 0.3 & 2.0 & $4.0 \times 10^{-7}-1.0 \times 10^{-2}$ & $3.3 \times 10^{-7}$ & $-58.4 \pm 0.2$ & 0.9991 \\
\hline $24^{\mathrm{s}}$ & 40.6 & 45.0 & 10.2 & 0.3 & 3.9 & $4.0 \times 10^{-7}-1.0 \times 10^{-2}$ & $2.5 \times 10^{-7}$ & $-58.9 \pm 0.2$ & 0.9992 \\
\hline 25 & 38.1 & 45.6 & 9.9 & 0.2 & 6.2 & $4.0 \times 10^{-7}-1.0 \times 10^{-2}$ & $3.6 \times 10^{-7}$ & $-57.4 \pm 0.3$ & 0.9986 \\
\hline 26 & 42.7 & 44.9 & 8.1 & 0.3 & 4.0 & $4.0 \times 10^{-7}-1.0 \times 10^{-2}$ & $3.7 \times 10^{-7}$ & $-57.1 \pm 0.4$ & 0.9977 \\
\hline
\end{tabular}

* Standard deviation (5 replicates); ${ }^{\mathrm{s}}$ - selected carbon paste electrode.

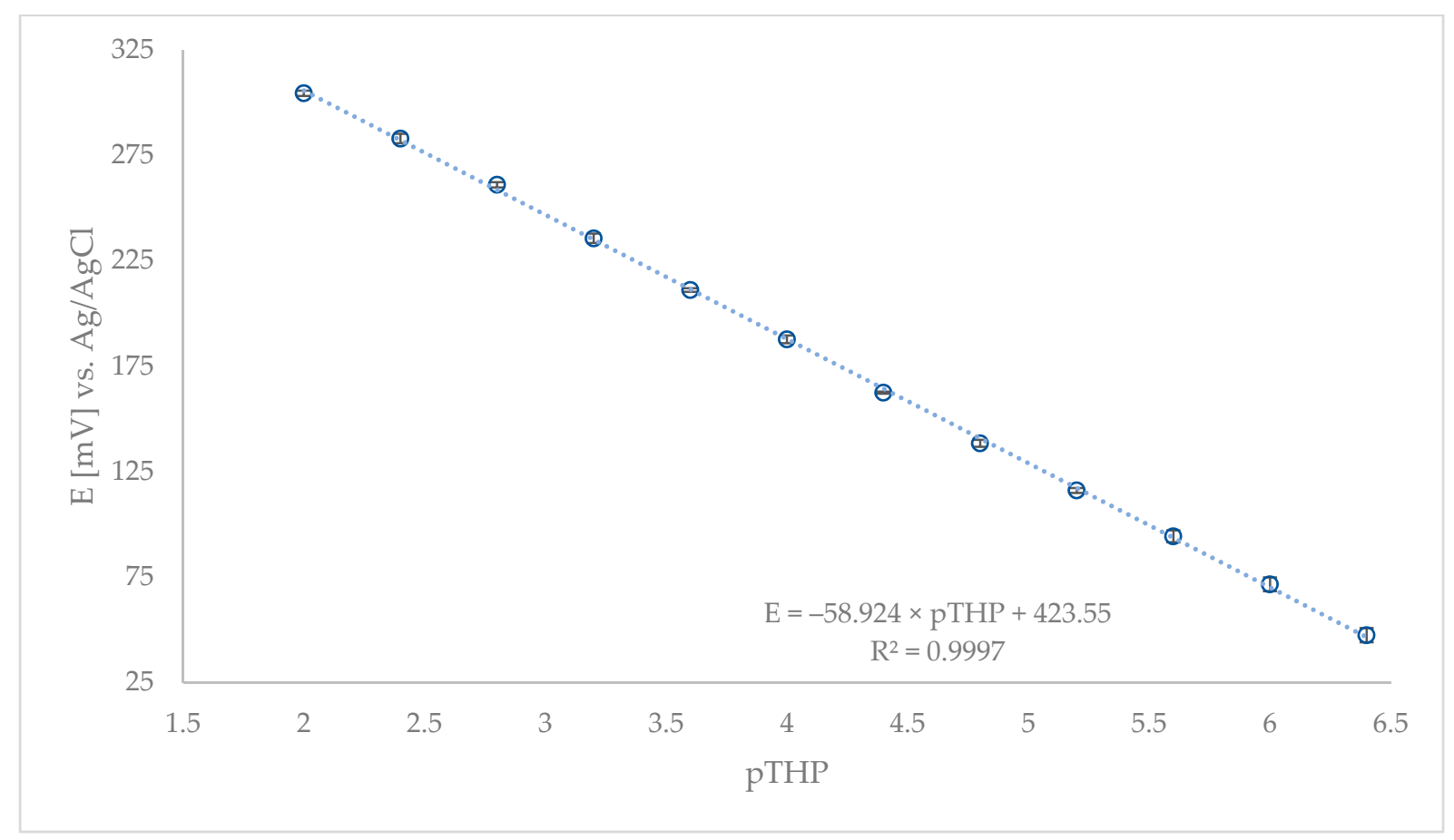

Figure 3. Calibration graph of the optimized-no. 24 CPE. 


\subsubsection{The Influence of $\mathrm{pH}$ on the Electrode Response}

$\mathrm{pH}$ changes on the $\mathrm{CP}$ electrode response were carried out in $1.0 \times 10^{-4}, 1.0 \times 10^{-5} \mathrm{M}$, and $1.0 \times 10^{-6} \mathrm{M}$ THP solutions, varying the $\mathrm{pH}$ from 1.2 to 8.4 by small additions of $\mathrm{HCl}$ or $\mathrm{NaOH}$ solutions. The result obtained shows that the electrode can be safely used for THP determination over the $\mathrm{pH}$ range of 2.4-5.2, as shown in Figure 4. As can be seen, the potential became gradually lower above $\mathrm{pH}$ 5.2, which may be caused by the $\mathrm{OH}^{-}$ ions penetrating the membrane and forming THP free base and consequently decreasing the amount of protonated species in the test solutions. One of the explanations of why the potential also decreases at $\mathrm{pH}$ values below 2.4 , could be that $\mathrm{H}_{3} \mathrm{O}^{+}$ions can compete with THP ions due to their high mobility and thus interfere with the measuring signal [5]. No significant deviations of the described $\mathrm{pH}$ effect were observed at different concentrations of THP.

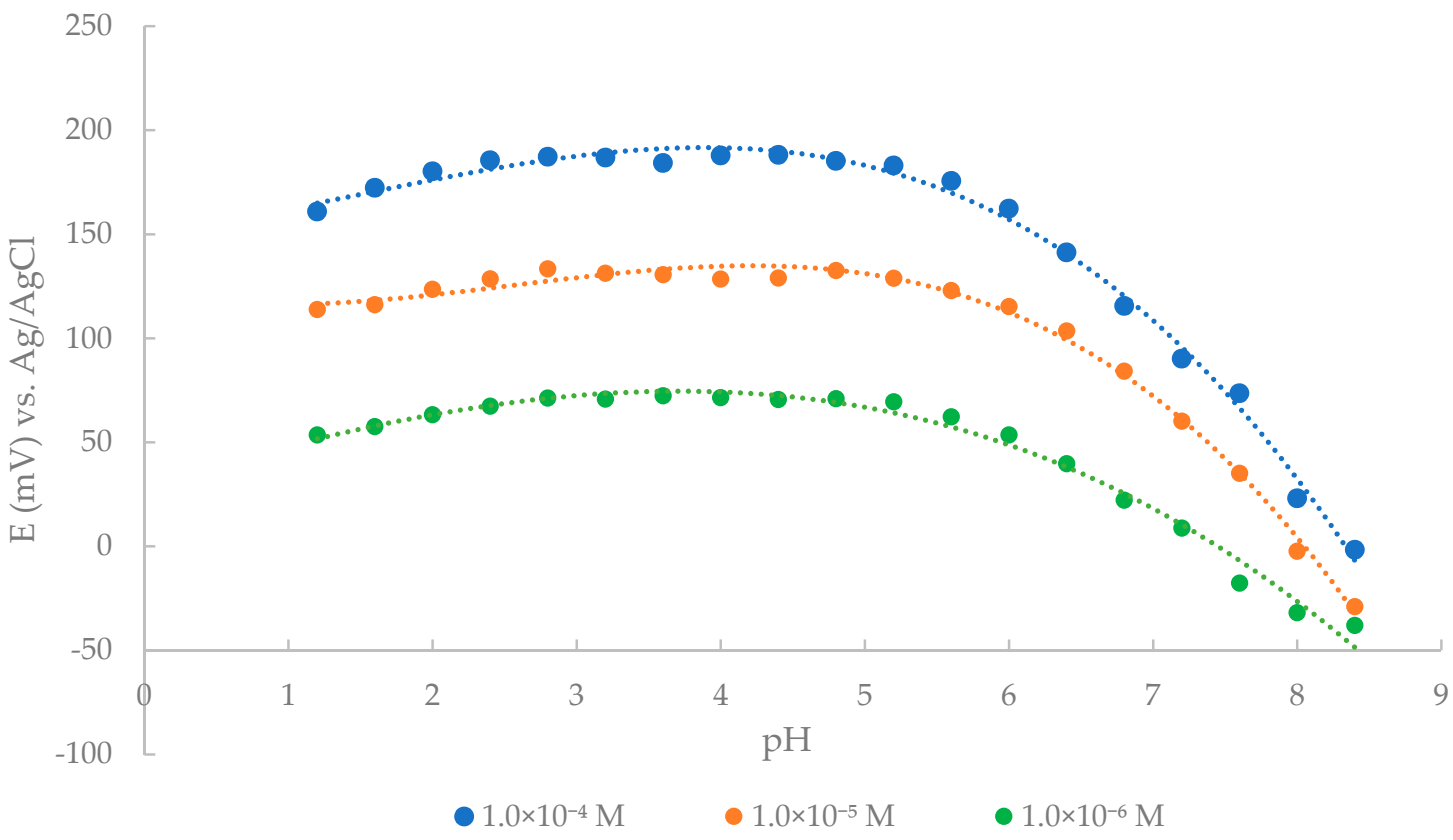

Figure 4. Effect of $\mathrm{pH}$ on the potential response of the proposed CPE.

\subsubsection{Dynamic Response Time, Reversibility, and Lifetime of the Electrode}

The results on the determination of the response time, reversibility, and hysteresis of the electrodes are also of great importance for the subsequent analytical applications. The practical dynamic response time and reversibility of the prepared electrode were tested by measuring the time required to reach a steady-state potential value within $\pm 1 \mathrm{mV}$ after successive immersions of the electrode in a series of THP solutions, each of which had a 10 -fold increase in concentration from $1 \times 10^{-6}$ to $1 \times 10^{-2} \mathrm{M}$. As can be seen, the electrode reached a steady potential in a particularly short time (within $\leq 5 \mathrm{~s}$ ).

To assess reversibility, the same procedure was performed but in the reverse direction (from high to low THP concentration). The results showed that the electrode required a longer time (within $\leq 13 \mathrm{~s}$ ) to respond to changes in analyte concentration and to reach equilibrium values assuming residual THP was still adsorbed on the electrode surface. The electrode was reversible and showed no memory effect toward previous solutions with higher THP concentration (Figure 5). After four measurement cycles, the electrode became unusable while the electrode sensitivity was lost due to permeability and disintegration of the surface. This was resolved by renewing the membrane surface as previously described. 


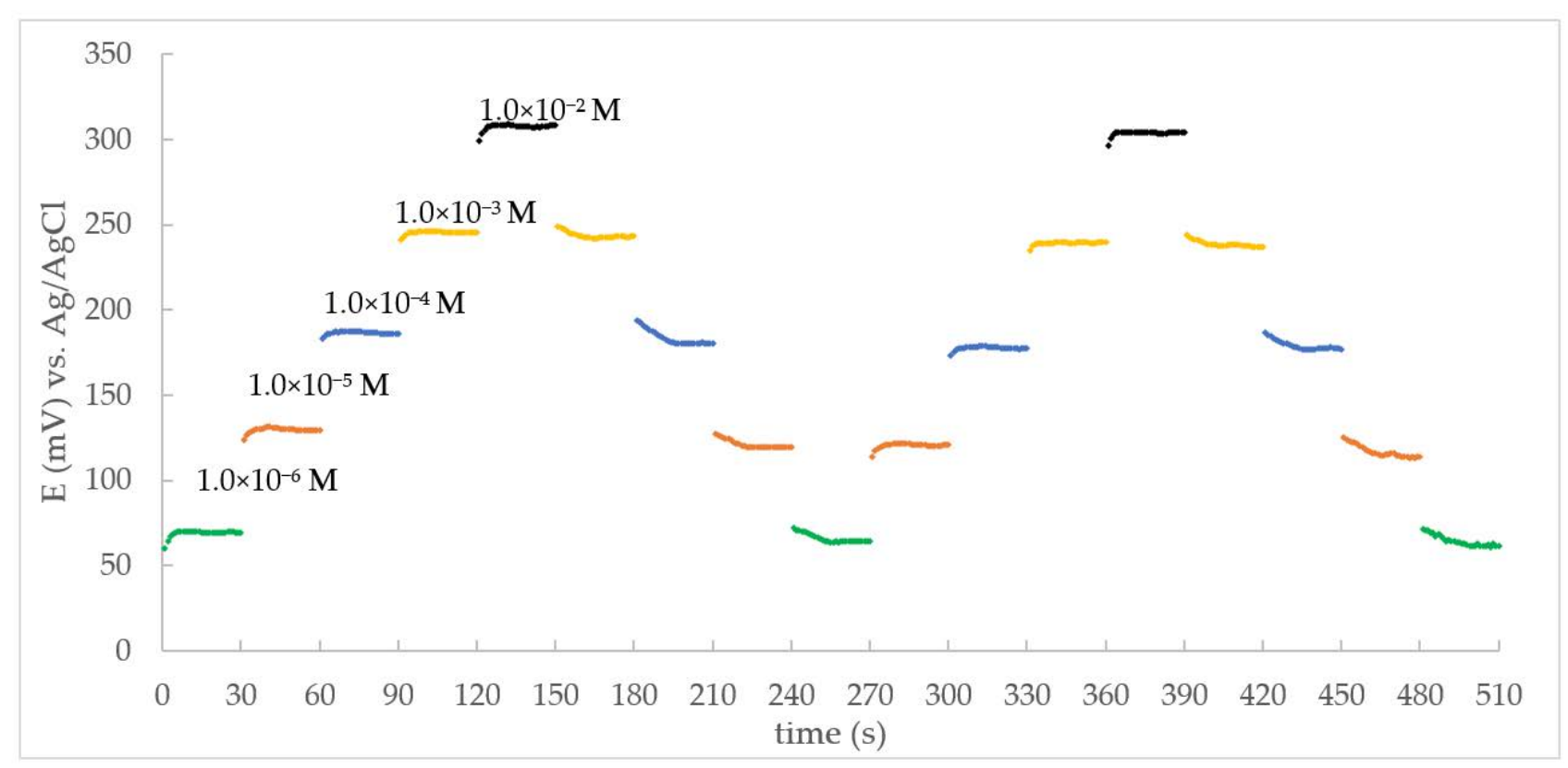

Figure 5. Dynamic response time and reversibility of the proposed CPE.

The lifetime of the proposed CPE was investigated by periodically calibrating it in THP solutions and calculating the slope. Figure S7 in the supplementary materials shows that no remarkable change was observed in the slopes of the calibration curves within 19 days. The stability of the proposed CPE is due to the renewability of the surface. Over the next 11 days, as can be seen, there was a decrease in the slope from 57.4 to $49.2 \mathrm{mV}$ /decade.

\subsubsection{Interference Studies}

Since the samples may contain varying numbers of interfering species, selectivity was investigated as an important factor of the electrode applicability. Interfering ions obstruct the analyte ions and give erroneous results during measurements. Generally, selectivity is the ability of a sensor to discriminate between analyte ions and interfering ions. Selectivity coefficients express the numerical value of selectivity for each interfering species tested separately. They are defined using various equations depending on the chosen IUP AC method. A lower value of the selectivity coefficient means that the electrode can determine the target species without noticeable interference. The selectivity coefficients of the proposed CPE were investigated using the matched potential method (MPM) and estimated using the following equation:

$$
K_{\mathrm{THP}, \mathrm{INT}}^{p o t}=\frac{a_{\mathrm{THP}}^{\prime}-a_{\mathrm{THP}}}{a_{\mathrm{INT}}}
$$

where $a_{\mathrm{THP}}$ is the known activity of the added THP solution into a reference THP solution that contains a fixed activity $\left(a_{\mathrm{THP}}\right)$ and $a_{\mathrm{INT}}$ is the activity of the added tested interfering species producing the same potential change.

According to the literature, several compounds were included in the interference study because they are either a common excipient of the medications or an ion present in urine $[36,41,59]$. Interferences to some nonsteroidal anti-inflammatory analgesics as well as to an antidepressant were also tested. As shown in Table 2, the proposed electrode demonstrated high selectivity toward THP over the tested interfering ions and is accordingly usable for analytical measurements. 
Table 2. Selectivity coefficients $\left(-\log K_{\mathrm{THP}, \mathrm{INT}}^{\text {pot }}\right)$ of various ions for proposed CPE.

\begin{tabular}{cc}
\hline Foreign Ions & $\left(-\log K_{T H P, I N T}^{\text {pot }}\right)$ \\
\hline $\mathrm{K}^{+}$ & -4.19 \\
$\mathrm{NH}_{4}^{+}$ & -4.36 \\
$\mathrm{Ca}^{2+}$ & -3.81 \\
$\mathrm{Mg}^{2+}$ & -3.62 \\
$\mathrm{Zn}^{2+}$ & -3.72 \\
$\mathrm{~Pb}^{2+}$ & -3.18 \\
$\mathrm{Fe}^{3+}$ & -3.26 \\
glucose & -3.46 \\
galactose & -3.53 \\
fructose & -3.94 \\
acetylsalicylic acid & -4.11 \\
paracetamol & -3.95 \\
maprotiline hydrochloride & -2.84 \\
\hline
\end{tabular}

\subsubsection{Analytical Application and Real Sample Analysis}

The accuracy and precision were tested by seven determinations at three different concentration levels in pure solutions. The proposed CPE was applied to determine THP in pharmaceutical preparations and spiked urine samples using the calibration curve method, the standard addition method, and potentiometric titration.

The direct potentiometric determination of THP using the calibration curve gave average recovery of $98.7 \pm 1.0 \%, 97.6 \pm 1.7 \%$, and $97.5 \pm 1.9 \%$ in pure solutions, tablets, and urine, respectively. Despite the fact that this method exhibits higher deviations compared to the other two, the obtained results show a very high accuracy, especially because results of studies obtained at very low THP concentrations in real samples were also included in the statistical analysis.

The standard addition method was used to minimize the potential matrix effect that may have interfered with the analyte, THP, to obtain better recoveries and improved standard deviations of the tested samples. The average recoveries were $99.3 \pm 0.4 \%$, $98.7 \pm 0.9 \%$, and $101.3 \pm 1.0 \%$ in pure solutions, tablets, and urine, respectively. The model obtained for this method is shown in Figure S8.

Furthermore, the developed electrode was investigated in conjunction with an $\mathrm{Ag} / \mathrm{AgCl}$ reference electrode as an end point indicator electrode for titrations of THP with NaTPB or PTA as titrant. The end point of the titration was determined as the mean of the minimum of the first derivatives of seven replicates of the titration curves. The well-defined S-shape of the titration curve and the large potential change at the end point suggest that highly accurate results could be obtained (Figure 6 and Figure S9). The results obtained by this method were similar to those obtained by the standard addition method.

The results of the real sample analysis are summarized in Table 3. The content of THP showed good agreement with the declared (tablets) or expected (spiked urine samples) amounts in the real samples tested as well as in the pure solutions. 


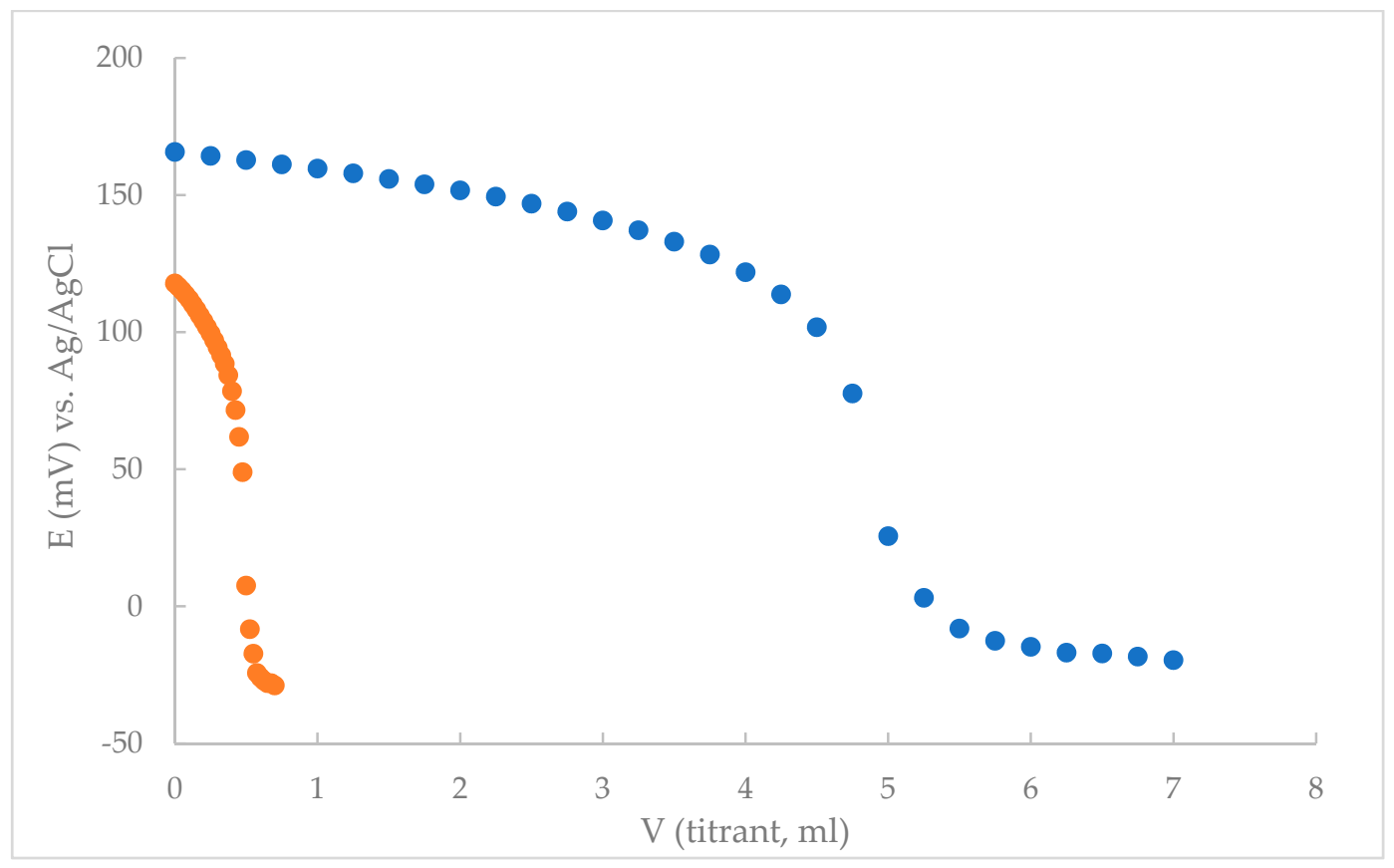

Figure 6. A typical potentiometric titration curve for $50 \mathrm{~mL}$ aliquot of Parkopan tablets.

Table 3. Analysis of THP in pure solution, pharmaceutical formulation, and spiked urine sample using different methods.

\begin{tabular}{|c|c|c|c|}
\hline & & Taken THP (mol L $\left.{ }^{-1}\right)$ & Recovery $\pm \mathbf{R S D} *(\%)$ \\
\hline \multirow{6}{*}{ Pure solutions } & \multirow{2}{*}{ Direct method } & $1.0 \times 10^{-4}$ & $99.0 \pm 0.6$ \\
\hline & & $1.0 \times 10^{-5}$ & $98.4 \pm 1.3$ \\
\hline & \multirow{2}{*}{$\begin{array}{l}\text { Standard addition } \\
\text { method }\end{array}$} & $1.0 \times 10^{-4}$ & $99.4 \pm 0.4$ \\
\hline & & $1.0 \times 10^{-5}$ & $99.2 \pm 0.5$ \\
\hline & \multirow{2}{*}{$\begin{array}{l}\text { Potentiometric } \\
\text { titration }\end{array}$} & $1.0 \times 10^{-4}$ & $99.4 \pm 0.3$ \\
\hline & & $1.0 \times 10^{-5}$ & $99.2 \pm 0.6$ \\
\hline \multirow{6}{*}{ Parkopan tablets } & \multirow{2}{*}{ Direct method } & $1.0 \times 10^{-4}$ & $98.1 \pm 1.4$ \\
\hline & & $1.0 \times 10^{-5}$ & $97.0 \pm 2.0$ \\
\hline & \multirow{2}{*}{$\begin{array}{l}\text { Standard addition } \\
\text { method }\end{array}$} & $1.0 \times 10^{-4}$ & $98.9 \pm 0.6$ \\
\hline & & $1.0 \times 10^{-5}$ & $98.4 \pm 1.0$ \\
\hline & \multirow{2}{*}{$\begin{array}{l}\text { Potentiometric } \\
\text { titration }\end{array}$} & $1.0 \times 10^{-4}$ & $98.9 \pm 0.7$ \\
\hline & & $1.0 \times 10^{-5}$ & $98.7 \pm 1.0$ \\
\hline \multirow{6}{*}{ Spiked urine samples } & \multirow{2}{*}{ Direct method } & $1.0 \times 10^{-4}$ & $98.2 \pm 1.7$ \\
\hline & & $1.0 \times 10^{-5}$ & $96.8 \pm 1.8$ \\
\hline & \multirow{2}{*}{$\begin{array}{l}\text { Standard addition } \\
\text { method }\end{array}$} & $1.0 \times 10^{-4}$ & $100.9 \pm 0.8$ \\
\hline & & $1.0 \times 10^{-5}$ & $101.7 \pm 1.1$ \\
\hline & \multirow{2}{*}{$\begin{array}{l}\text { Potentiometric } \\
\text { titration }\end{array}$} & $1.0 \times 10^{-4}$ & $101.0 \pm 0.9$ \\
\hline & & $1.0 \times 10^{-5}$ & $98.6 \pm 1.0$ \\
\hline
\end{tabular}

*Seven replicates.

\section{Conclusions}

In this work, a novel type of rGO based carbon paste electrode was presented as a useful analytical tool for the rapid, low-cost, and simple determination of THP in pure form and in real samples using the calibration curve method, the standard addition method, and potentiometric titration. SEM and BET were used to characterize the synthesized GO and $\mathrm{rGO}$, respectively. The proposed CPE showed good performance characteristics with minimal sample pretreatment and gave precise and accurate results down to a concentration level of $4.0 \times 10^{-7} \mathrm{M}$. It showed excellent selectivity, Nernstian behavior, reproducibility, stability with fast dynamic response time, and adequate lifetime. The surface of the 
electrode was easily regenerated. Recommendation to use the described CPE for THP determination even in routine laboratories can be made.

Supplementary Materials: Supplementary Materials are available online at https://www.mdpi. com/article/10.3390/s21092955/s1.

Author Contributions: Conceptualization, M.K.; methodology, J.R., B.G., M.K., M.B.; investigation, J.R., E.G.; resources, M.K.; writing-original draft preparation, J.R.; writing-review and editing, B.G., E.G., M.B., M.K.; visualization, J.R., E.G.; supervision, M.B., B.G., M.K. All authors have read and agreed to the published version of the manuscript.

Funding: The authors acknowledged the financial support received from the programs P1-0153 and P1-0175 of the Slovenian Research Agency (ARRS).

Institutional Review Board Statement: Not applicable.

Informed Consent Statement: Informed consent was obtained from all subjects involved in the study.

Acknowledgments: The author J.R. would like to thank the Erasmus+ exchange program, under which he had the opportunity to spend 5 months in Ljubljana's as a member of Erasmus+ student exchange.

Conflicts of Interest: The authors declare no conflict of interest.

\section{References}

1. Downs, A.M.; Fan, X.; Donsante, C.; Jinnah, H.A.; Hess, E.J. Trihexyphenidyl rescues the deficit in dopamine neurotransmission in a mouse model of DYT1 dystonia. Neurobiol. Dis. 2019, 125, 115-122. [CrossRef]

2. Giachetti, A.; Giraldo, E.; Ladinsky, H.; Montagna, E. Binding and functional profiles of the selective M1 muscarinic receptor antagonists trihexyphenidyl and dicyclomine. Br. J. Pharmacol. 1986, 89, 83-90. [CrossRef] [PubMed]

3. Harris, M.K.; Shneyder, N.; Borazanci, A.; Korniychuk, E.; Kelley, R.E.; Minagar, A. Movement Disorders. Med. Clin. N. Am. 2009, 93, 371-388. [CrossRef]

4. He, H.; McKay, G.; Wirshing, B.; Midha, K.K. Development and Application of a Specific and Sensitive Radioimmunoassay for Trihexyphenidyl to a Pharmacokinetic Study in Humans. J. Pharm. Sci. 1995, 84, 561-567. [CrossRef] [PubMed]

5. Abu Shawish, H.M.; Elhabiby, M.; Abu Aziz, H.S.; Saadeh, S.M.; Tbaza, A. Determination of Trihexyphenidyl hydrochloride drug in tablets andurine using a potentiometric carbon paste electrode. Sens. Actuators B Chem. 2016, 235, 18-26. [CrossRef]

6. Patel, A.; Shrivastava, A.; Jain, A.; Singh, G. Method Development and Validation for estimation of Trihexyphenedyl Hydrochloride in Tablet Dosage Forms. Asian J. Res. Chem. 2009, 2, 104-107.

7. Lovejoy, D.J. A rapid gas chromatographic method for the determination of benzhexol hydrochloride. J. Chromatogr. A 1971, 57, 137-138. [CrossRef]

8. Kintz, P.; Godelar, B.; Mangin, P.; Chaumont, A.J.; Lugnier, A.A. Identification and quantification of trihexyphenidyl and its hydroxylated metabolite by gas chromatography with nitrogen-phosphorus detection. J. Anal. Toxicol. 1989, 13, 47-49. [CrossRef]

9. Owen, J.A.; Sribney, M.; Lawson, J.S.; Delva, N.; Letemendia, F.J.J. Capillary gas chromatography of trihexyphenidyl, procyclidine and cycrimine in biological fluids. J. Chromatogr. B Biomed. Sci. Appl. 1989, 494, 135-142. [CrossRef]

10. Ishii, A.; Nishikawa, M.; Seno, H.; Kumazawa, T.; Watanabe, K.; Suzuki, O. Determination of trihexyphenidyl in body fluids by gas chromatography with surface ionization detection. Forensic Toxicol. 1994, 12, 241-246.

11. Patel, D.; Patel, J. Development and validation of RP-HPLC method for simultaneous estimation of Risperidone and Trihexyphenidyl hydrochloride in tablet dosage forms. Int. J. Pharm. Sci. Rev. Res. 2010, 4, 85-88.

12. Parvataneni, S.V.; Nagarjuna, P.J. Development and validation for the simultaneous determination of trifluoperazine hydrochloride and trihexyphenidyl hydrochloride in a solid oral dosage form by RP-HPLC. World J. Pharm. Pharm. Sci. 2014, 3, $1021-1031$.

13. Pradas, T.N.V.; Sivakumar, M. HPLC quantification of a tricomponent psychiatric formulation containing chlorpromazine, trifluoperazine and trihexyphenidyl. Pharmazie 1992, 47, 231.

14. Mahadik, K.R.; Aggarwal, H.; Kaul, N. Development and validation of HPLC method for simultaneous estimation of trihexyphenidyl hydrochloride and chlorpromazine hydrochloride from tablet dosage form. Indian Drugs 2002, 39, 441-445.

15. Čápka, V.; Xu, Y.; Hong Chen, Y. Stereoselective determination of trihexyphenidyl in human serum by LC-ESI-MS. J. Pharm. Biomed. Anal. 1999, 21, 507-517. [CrossRef]

16. Čápka, V.; Xu, Y. Simultaneous determination of enantiomers of structurally related anticholinergic analogs in human serum by liquid chromatography-electrospray ionization mass spectrometry with on-line sample cleanup. J. Chromatogr. B Biomed. Sci. Appl. 2001, 762, 181-192. [CrossRef]

17. Yuan, S.-L.; Li, X.-F.; Jiang, X.-M.; Zhang, H.-X.; Zheng, S.-K. Simultaneous Determination of 13 Psychiatric Pharmaceuticals in Sewage by Automated Solid Phase Extraction and Liquid Chromatography-Mass Spectrometry. Chin. J. Anal. Chem. 2013, 41, 49-56. [CrossRef] 
18. Borkar, A.; Wate, S. Simultaneous Spectrophotometric Estimation of Haloperidol and Trihexyphenidyl in Tablets. Indian J. Pharm. Sci. 2010, 72, 265. [CrossRef] [PubMed]

19. Vargas, G.; Havel, J.; Babáčková, L.; Patočka, J. Determination of drugs used as anti-Parkinson's disease drugs in urine and serum by capillary electrophoresis. J. Capill. Electrophor. Microchip Technol. 1998, 5, 153-158.

20. Li, H.; Wang, P.; Li, C.; Wang, H.; Zhang, H. Steroselective determination of trihexyphenidyl using carboxylmethyl- $\beta$-cyclodextrin by capillary electrophoresis with field-amplified sample stacking. Microchem. J. 2008, 89, 34-41. [CrossRef]

21. Chalavi, S.; Fakhari, A.R.; Nojavan, S. Development of a modified partial filling method in capillary electrophoresis using two chiral plugs for the simultaneous enantioseparation of chiral drugs: Comparison with mixed chiral selector capillary electrophoresis. J. Chromatogr. A 2018, 1567, 211-218. [CrossRef] [PubMed]

22. Papke, E. Gravimetric methods for determination of Parkopan, Spasman and Dispasmol. 2. On the analysis of some spasmolytics. Pharmazie 1968, 23, 148-150. [PubMed]

23. Bozsai, G.; Vastagh, G. The polarographic determination of primidone and trihexyphenidyl (benzhexol). Pharm Zentralhalle Dtschl 1964, 103, 403-408. [PubMed]

24. Afkhami, A.; Shirzadmehr, A.; Madrakian, T.; Bagheri, H. New nano-composite potentiometric sensor composed of graphene nanosheets/thionine/molecular wire for nanomolar detection of silver ion in various real samples. Talanta 2015, 131, 548-555. [CrossRef] [PubMed]

25. Gupta, V.K.; Agarwal, S.; Singhal, B. Potentiometric assay of antipsychotic drug (Ziprasidone Hydrochloride) in pharmaceuticals, serum and urine. Int. J. Electrochem. Sci. 2011, 6, 3036-3056.

26. Gupta, V.K.; Singh, A.K.; Gupta, B. Schiff bases as cadmium(II) selective ionophores in polymeric membrane electrodes. Anal. Chim. Acta 2007, 583, 340-348. [CrossRef]

27. Svancara, I.; Kalcher, K.; Walcarius, A.; Vytras, K. Electroanalysis with Carbon Paste Electrodes; CRC Press Taylor and Francis Group: Boca Raton, FL, USA, 2012; ISBN 9781439830208.

28. Ganjali, M.R.; Khoshsafar, H.; Faridbod, F.; Shirzadmehr, A.; Javanbakht, M.; Norouzi, P. Room temperature ionic liquids (rtils) and multiwalled carbon nanotubes (mwcnts) as modifiers for improvement of carbon paste ion selective electrode response; A comparison study with pvc membrane. Electroanalysis 2009, 21, 2175-2178. [CrossRef]

29. Mashhadizadeh, M.H.; Ramezani, S.; Ebrahimi, S. Potentiometric determination of nanomolar concentration of Cu (II) using a carbon paste electrode modified by a self-assembled mercapto compound on gold nanoparticles. Sens. Actuators B Chem. 2012, 169, 305-311. [CrossRef]

30. Rouhani, M.; Soleymanpour, A. A new selective carbon paste electrode for potentiometric analysis of olanzapine. Measurement 2019, 140, 472-478. [CrossRef]

31. El-Kosasy, A.M.; Abdel Rahman, M.H.; Abdelaal, S.H. Graphene nanoplatelets in potentiometry: A nanocomposite carbon paste and PVC based membrane sensors for analysis of Vilazodone $\mathrm{HCl}$ in plasma and milk samples. Talanta 2019, 193, 9-14. [CrossRef]

32. Gupta, V.K.; Arunima, N.; Singhal, B.; Agarwal, S. Recent advances on potentiometric membrane sensors for pharmaceutical analysis. Comb. Chem. High Throughput Screen. 2011, 14, 284-302. [CrossRef] [PubMed]

33. Ammar, R.A. A new atomoxetine hydrochloride selective electrode and its pharmaceuticals application. Int. J. Pharm. Sci. Rev. Res. 2016, 36, 242-246.

34. El-Tohamy, M.; Razeq, S.; El-Maamly, M.; Shalaby, A. Polymeric membrane sensors for direct determination of tricyclic antidepressant Clomipramine hydrochloride in pharmaceutical formulations and biological fluids. Med. Chem. Anal. 2014, 4, 130-140.

35. Issa, Y.M.; Khorshid, A.F. Using PVC ion-selective electrodes for the potentiometric flow injection analysis of distigmine in its pharmaceutical formulation and biological fluids. J. Adv. Res. 2011, 2, 25-34. [CrossRef]

36. Al-Harbi, E.A.; Abdelrahman, M.H.; El-Kosasy, A.M. Ecofriendly Long Life Nanocomposite Sensors for Determination of Carbachol in Presence of Choline: Application in Ophthalmic Solutions and Biological Fluids. Sensors 2019, 19, $2357-2368$. [CrossRef] [PubMed]

37. Issa, Y.M.; Attia, F.M.A.; Sherif, O.E.; Dena, A.S.A. Potentiometric and surface topography studies of new carbon-paste sensors for determination of thiamine in Egyptian multivitamin ampoules. Arab. J. Chem. 2017, 10, 751-760. [CrossRef]

38. Rassi, S.F. Chemically modified carbon paste ion-selective electrodes for determination of atorvastatin calcium in pharmaceutical preparations. Anal. Chem. Res. 2017, 12, 65-73. [CrossRef]

39. Abu Shawish, H.M.; Almonem, K.I.A.; Saadeh, S.M.; Al-lham, W.S. Determination of haloperidol drug in ampoules and in urine samples using a potentiometric modified carbon paste electrode Hazem. Measurement 2016, 78, 180-186. [CrossRef]

40. Dehnavi, A.; Soleymanpour, A. New chemically modified carbon paste sensor for nanomolar concentration measurement of rifampicin in biological and pharmaceutical media. Mater. Sci. Eng. C 2019, 94, 403-409. [CrossRef]

41. Frag, E.Y.; El Badry Mohamed, M.; Mohamed, G.G.; Ebrahim, M.S. Selective potentiometric sensors for the determination of butenafine hydrochloride in a cream formulation. Microchem. J. 2020, 157, 104870. [CrossRef]

42. Afzali, M.; Mostafavi, A.; Shamspur, T. Designing an Au/reduced graphene oxide modified carbon paste electrode for the electrochemical quantification of agnuside. Sens. Actuators B Chem. 2019, 290, 188-194. [CrossRef]

43. Yang, S.; Li, G.; Wang, G.; Zhao, J.; Qiao, Z.; Qu, L. Decoration of chemically reduced graphene oxide modified carbon paste electrode with yttrium hexacyanoferrate nanoparticles for nanomolar detection of rutin. Sens. Actuators B Chem. 2015, 206, 126-132. [CrossRef] 
44. Jawanjal, P.M.; Patil, P.B.; Patil, J.; Waghulde, M.; Naik, J.B. Development of Graphene Oxide-Trihexyphenidyl Hydrochloride Nanohybrid and Release behavior. Curr. Environ. Eng. 2019, 6, 134-140. [CrossRef]

45. Elashery, S.E.A.; Frag, E.Y.; Sleim, A.A.E. Novel and selective potentiometric sensors for Cinchocaine $\mathrm{HCl}$ determination in its pure and Co-formulated dosage form: A comparative study of in situ carbon sensors based on different ion pairing agents. Measurement 2020, 173, 108549. [CrossRef]

46. Reinhoudt, D.N.; Engbersen, J.F.J.; Brzozka, Z.; van der Vlekkert, H.H.; Honig, G.W.N.; Holterman, H.A.J.; Verkerk, U.H. Development of Durable K+-Selective Chemically Modified Field Effect Transistors with Functionalized Polysiloxane Membranes. Anal. Chem. 1994, 66, 3618-3623. [CrossRef]

47. Hočevar, S.B.; Ogorevc, B. Preparation and characterization of carbon paste micro-electrode based on carbon nano-particles. Talanta 2007, 74, 405-411. [CrossRef] [PubMed]

48. Lin, J.; Wei, Z.; Zhang, H.; Shao, M. Sensitive immunosensor for the label-free determination of tumor marker based on carbon nanotubes/mesoporous silica and graphene modified electrode. Biosens. Bioelectron. 2013, 41, 342-347. [CrossRef] [PubMed]

49. Bralić, M.; Prkić, A.; Radić, J.; Pleslić, I. Preparation of phosphate ion-selective membrane based on silver salts mixed with PTFE or carbon nanotubes. Int. J. Electrochem. Sci. 2018, 13, 1390-1399. [CrossRef]

50. Radić, J.; Bralić, M.; Kolar, M.; Genorio, B.; Prkić, A.; Mitar, I. Development of the New Fluoride Ion-Selective Electrode Modified with FexOy Nanoparticles. Molecules 2020, 25, 5213. [CrossRef]

51. Bagheri, H.; Shirzadmehr, A.; Rezaei, M. Designing and fabrication of new molecularly imprinted polymer-based potentiometric nano-graphene/ionic liquid/carbon paste electrode for the determination of losartan. J. Mol. Liq. 2015, 212, 96-102. [CrossRef]

52. Shirzadmehr, A.; Afkhami, A.; Madrakian, T. A new nano-composite potentiometric sensor containing an $\mathrm{Hg} 2+-i o n$ imprinted polymer for the trace determination of mercury ions in different matrices. J. Mol. Liq. 2015, 204, 227-235. [CrossRef]

53. Ganjali, M.R.; Faridbod, F.; Davarkhah, N.; Shahtaheri, S.J.; Norouzi, P. All solid state graphene based potentiometric sensors for monitoring of mercury ions in waste water samples. Int. J. Environ. Res. 2015, 9, 333-340. [CrossRef]

54. Marcano, D.C.; Kosynkin, D.V.; Berlin, J.M.; Sinitskii, A.; Sun, Z.; Slesarev, A.; Alemany, L.B.; Lu, W.; Tour, J.M. Improved synthesis of graphene oxide. ACS Nano 2010, 4, 4806-4814. [CrossRef]

55. Xu, J.; Wang, Y.; Hu, S. Nanocomposites of graphene and graphene oxides: Synthesis, molecular functionalization and application in electrochemical sensors and biosensors. A review. Microchim. Acta 2017, 184, 1-44. [CrossRef]

56. Chen, J.; Zhang, W.-D.; Ye, J.S. Nonenzymatic electrochemical glucose sensor based on MnO2/MWNTs nanocomposite. Electrochem. Commun. 2008, 10, 1268-1271. [CrossRef]

57. Nosan, M.; Mario, L.; Jerman, I.; Kolar, M.; Katsounaros, I. Understanding the Oxygen Reduction Reaction Activity of Quasi-1D and 2D N-Doped Heat-Treated Graphene Oxide Catalysts with Inherent Metal Impurities. ACS Appl. Energy Mater. 2021. [CrossRef]

58. Khorshid, A.F.; Issa, Y.M. Modified carbon paste sensor for the potentiometric determination of neostigmine bromide in pharmaceutical formulations, human plasma and urine. Biosens. Bioelectron. 2014, 51, 143-149. [CrossRef] [PubMed]

59. Khorshid, A.F. New analysis of clopidogrel bisulfate in plavix tablet and human biological fluids utilizing chemically modified carbon paste sensor. Arab. J. Chem. 2019, 12, 1740-1750. [CrossRef]

60. Nezamzadeh-Ejhieh, A.; Masoudipour, N. Application of a new potentiometric method for determination of phosphate based on a surfactant-modified zeolite carbon-paste electrode (SMZ-CPE). Anal. Chim. Acta 2010, 658, 68-74. [CrossRef] [PubMed]

61. Rosatzin, T.; Bakker, E.; Suzuki, K.; Simon, W. Lipophilic and immobilized anionic additives in solvent polymeric membranes of cation-selective chemical sensors. Anal. Chim. Acta 1993, 280, 197-208. [CrossRef] 